\title{
Erratum to: Nitrate and Nitrogen Oxides: Sources, Health Effects and Their Remediation
}

\author{
Khalid Rehman Hakeem, Muhammad Sabir, Munir Ozturk, \\ Mohd. Sayeed Akhtar, and Faridah Hanum Ibrahim
}

Erratum to:

Chapter 5 in: P. de Voogt (ed.), Reviews of Environmental

Contamination and Toxicology, Volume 242, Reviews of Environmental Contamination and Toxicology 242, DOI 10.1007/398_2016_11

The original version of this chapter was inadvertently published with incorrect list of authors. The correct author list should read Khalid Rehman Hakeem, Muhammad Sabir, Munir Ozturk, Mohd. Sayeed Akhtar, and Faridah Hanum Ibrahim. The authors Muhammad Ashraf and Muhammad Sajid Aqeel Ahmad were removed from the list upon their own request and with consent from all co-authors.

The original chapter was corrected.

The updated original online version for this chapter can be found at http://dx.doi.org/10.1007/398_2016_11 